\title{
Tailoring microstructure and texture of annealed Al-Mn alloy through the variation of homogenization and prior cold deformation strain
}

\author{
X.W. Fang ${ }^{\mathrm{a}}$, H. Xiao ${ }^{\mathrm{a}}$, K. Marthinsen ${ }^{\mathrm{b}}$, A. Belyakov ${ }^{\mathrm{c}}$, X.Y. Fang ${ }^{\mathrm{d}}$, Ke Huang, \\ ${ }^{\text {a }}$ State Key Laboratory of Mechanical Manufacturing System, School of Mechanical Engineering, Xi'an Jiaotong University, 710049 Xi'an, China \\ ${ }^{\mathrm{b}}$ Department of Materials Science and Engineering, Norwegian University of Science and Technology, N-7491 Trondheim, Norway \\ ${ }^{\mathrm{c}}$ Belgorod State University, Pobeda 85, Belgorod 308015, Russia \\ ${ }^{\mathrm{d}}$ School of Mechanical Engineering, Shandong University of Technology, Zibo 255000, China
}

A R T I C L E IN F O

\section{Keywords:}

Recrystallization

Texture

Grain structure

Precipitation

Particles

Zener pinning

\begin{abstract}
A B S T R A C T
The grain structures and crystallographic textures desired for various applications of aluminium alloys are usually modified by recrystallization during annealing. In this study, the interactions between recrystallization and precipitation were investigated using the same Al-Mn alloy but with different homogenization procedures (which gives different microchemistries in terms of solute level and second phase particle state) and prior cold deformation strains, both of which are easy to realize in industrial practice. The results show that recrystallization and precipitation kinetics are both promoted at large deformations but their mutual interactions also exist. Recrystallization is retarded by precipitation through the suppressing of nucleation and pinning of grain boundary migration, while early finish of recrystallization delays precipitation by reducing their nucleation sites. The delicate interplay between recrystallization and precipitation during annealing leads to different combinations of grain structures and textures. An equiaxed fine grain structure can be obtained when recrystallization is not affected by fine particles while the combined effects of a strong fibrous deformation structure, suppressed nucleation of recrystallization and preferential growth lead to a coarse elongated grain structure. Different crystallographic textures desired for typical applications of Al-Mn alloys can be obtained after annealing simply through the different combinations of homogenization procedures and prior cold deformations.
\end{abstract}

\section{Introduction}

AA3xxx-series alloys are extensively used in beverage can and automobile heat exchanger industries, due to their good combination of strength and ductility, as well as their excellent corrosion resistance. The main alloying element of this class of alloys is Mn, while other elements like $\mathrm{Mg}, \mathrm{Si}, \mathrm{Fe}$ and $\mathrm{Cu}$ are also frequently added to improve their mechanical properties. During solidification, most of Fe is consumed to form intermetallic constituent particles, while Mn mainly remains in solid solution. The limited solubility of $\mathrm{Mn}$ in an $\mathrm{Al}$ matrix [1] makes it unstable during subsequent thermo-mechanical processing (TMP) steps, the supersaturated Mn will therefore precipitate as Mnbearing dispersoids [2], which change the microchemistry (in terms of solute level and second phase particle state) of the alloy [3].

The desired microstructures of AA3xxx alloys vary with their application areas, e.g., fine grain structure is more suitable for fabricating beverage cans while coarse grain structure improves corrosion resistance of heat exchangers [4]. The anisotropy introduced by the crystallographic texture also poses challenges for the wider application of this category of aluminium alloys, e.g., earing is often observed during the deep drawing process. It should be noted that most thermomechanical processes promote rather than reduce crystallographic texture, which makes it a difficult task to control. The grain structure and crystallographic texture of AA3xxx alloys, which exhibit no bulk phase transformation during their thermal mechanical processing steps, are mostly optimised through recrystallization [5-7]. It thus appears that there is a strong academic and industrial interest in tailoring the microstructure and texture of the non-heat treatable Al 3xxx alloy products.

According to literature, different approaches have been attempted to tailor the grain structure and crystallographic texture of aluminium alloys. It is textbook knowledge that large cold deformation usually leads to fast recrystallization and fine grain structure since it brings both high driving force and nucleation rate [6]. Since deformation

\footnotetext{
* Corresponding author.

E-mail address: ke.huang@xjtu.edu.cn (K. Huang).
} 
texture is obviously dependent on strain level, it is not surprising that recrystallization textures also can be modified by changing the deformation strain $[8,9]$. The recrystallization texture can be further modified by changing the deformation texture through strain path changes during cold deformation, e.g. by unidirectional and multi-step cross rolling [10]. However, in real industrial practice, particularly during cold/hot rolling, it is very difficult to change the rolling direction since the width of the rolls is typically much smaller than the length of the rolled products.

Besides the effect of cold deformation, it has also been documented in the literature that grain size and crystallographic texture can change significantly during annealing when the microchemistry of the material varies, which can be realized by changing the homogenization procedures [11-13], annealing temperatures [3,14-17], as well as other processing parameters [18-21]. The change of microchemistry may significantly affect the recrystallization behaviour, leading to different grain structures and crystallographic textures. Most of the above-mentioned studies on tailoring of the grain structure and texture of $\mathrm{Al}$ alloys, however, focused only on one or two influencing factors together with limited testing conditions. Due to the lack of systematic studies on this aspect, some of the published literature have even given contradictory conclusions, because investigations on one single factor may mask the contribution of other not touched factors. It is thus concluded that, in addition to varying the annealing conditions, further investigations considering the joint effects of microchemistry and prior cold deformation are necessary to get an in-depth understanding of microstructure and texture evolution during annealing of supersaturated aluminium alloys.

In this work, the combined effect of homogenization procedures (varying the microchemistry of the material) and prior cold deformation on microstructure evolution during isothermal annealing of a coldrolled Al-Mn alloy was investigated. From the same starting as-cast material, three variants (C1-0, C1-2, C1-3), which are chosen to be consistent with previous studies on the same alloys (Refs. [3, 11, 12]), were obtained using different homogenization procedures. The three variants were then each cold-rolled to three different strain levels ( $\varepsilon=0.7,1.6$ and 3.0), before being isothermally annealed at 300,400 and $500{ }^{\circ} \mathrm{C}$. The recrystallization and precipitation kinetics, as well as the final grain structures and textures of the samples were investigated in terms of the variations of hardness, electrical conductivity and SEM (Scanning Electron Microscopy)-EBSD (Electron Backscattering Electron Diffraction) micrographs. Based on these results, the principles on tailoring microstructure and texture through the combination of varying homogenization procedures and prior cold deformation are discussed in detail.

\section{Experimental}

\subsection{Materials and thermal mechanical processing}

The as-received material from a Direct-chilling (DC)-cast extrusion billet was denoted as C1-0, with chemical composition of: Mn $0.4 \mathrm{wt} \%$, Fe $0.5 \mathrm{wt} \%$, Si $0.15 \mathrm{wt} \%$ and balance of Al. Some of the received material were then homogenized under two different conditions to get distinctly different microchemistries. The first category of samples was homogenized at $450{ }^{\circ} \mathrm{C}$ for $4 \mathrm{~h}$ with heating rate of $50{ }^{\circ} \mathrm{C} / \mathrm{h}$, hereafter named as C1-2. The second set of samples designated as C1-3 was subjected to a more complex two-step treatment procedure. The samples were first homogenized at a high temperature of $600{ }^{\circ} \mathrm{C}$ for $4 \mathrm{~h}$ with a heating rate of $50{ }^{\circ} \mathrm{C} / \mathrm{h}$, and then they were subsequently cooled at $25{ }^{\circ} \mathrm{C} / \mathrm{h}$ to a lower temperature of $500{ }^{\circ} \mathrm{C}$, where they were kept for another $4 \mathrm{~h}$. Both homogenized bulk- sample variants were immediately water quenched at the end of the heat-treatment.

The three variants of homogenized samples were cut and cold-rolled at room temperature with heavy lubrication to three different deformation strains, i.e., $\varepsilon=0.7, \varepsilon=1.6$ and $\varepsilon=3.0$. The rolled sheets were cut into small pieces and subsequently annealed in pre-heated salt bath (i.e., isothermal annealing) at different target temperatures $\left(300{ }^{\circ} \mathrm{C}, 400{ }^{\circ} \mathrm{C}\right.$ and $500{ }^{\circ} \mathrm{C}$ ) with varied holding times in the range of $5-10^{5} \mathrm{~s}$ before immediate water quenching.

\subsection{Microstructure and properties characterization}

The recrystallization and precipitation behaviour during annealing of the cold rolled samples were indirectly investigated by Vickers hardness (VHN) and electrical conductivity (EC) measurements, respectively. Eight measurements were conducted on the RD-TD plane of the sheet samples for both VHN and EC, from which their average values and standard deviations were derived. For the VHN, the measurements were performed using a load of $1 \mathrm{~kg}$, a loading speed of $100 \mu \mathrm{m} \mathrm{s}^{-1}$ and a loading time of $15 \mathrm{~s}$. The variation of VHN has been widely used to study the recrystallization during annealing since the increasing of recrystallization fraction decreases the VHN value and tedious metallographic examination is avoided. EC measurements were performed at room temperature with a Sigmascope EX 8 device. It has been reported in a similar alloy that the contents of Fe and $\mathrm{Si}$ elements in solid solution are very low [28], it is thus assumed that the variation of $\mathrm{Mn}$ content in the matrix of the investigated alloy is the main origin of EC evolution. Since the precipitation of Mn containing particles within the aluminium matrix increase its EC value, it can be used as a semi-quantitative way to estimate the precipitation behaviour of Mncontaining particles. The equivalent diameter $d$ and number density of both coarse constituent particles and fine dispersoids were measured from BSE (back-scattered electron) micrographs obtained in a Zeiss Ultra 55 FEG-SEM through the image analysis software of Image-J.

SEM-EBSD Orientation imaging maps with step size of $1-2 \mu \mathrm{m}$, were employed to analyse the microstructure and crystallographic texture of the deformed and annealed samples under various conditions. Different from the VHN and EC measurements, the EBSD/SEM micrographs presented in this paper were obtained from carefully prepared samples such that the rolling direction (RD) was kept along the horizontal direction and the normal direction (ND) is aligned to the vertical direction. From the EBSD maps, the crystallographic textures are presented in terms of orientation distribution functions (ODFs), where the orthotropic symmetry, harmonic series expansion method $(\mathrm{L}=22)$ and Gaussian half-width of $5^{\circ}$ were imposed. The average grain size $\left(\mathrm{d}_{\mathrm{Av}}\right)$ and crystallographic texture were measured by merging several EBSD maps together, in order to provide statistically reliable results, more details of which can be found in Ref [22].

\section{Results}

\subsection{The microstructure and microchemistry state before annealing}

The as-received variant C1-0 exhibits an equiaxed grain structure, with an average grain size of $\sim 140 \mu \mathrm{m}$, and a nearly random texture (typical for industrially as-cast materials), as shown in Fig. 1a. The subsequent homogenization procedures which lead to C1-2 and C1-3 variants do not further change the microstructure, as can be seen in Fig. $1 \mathrm{~b}$ and c. This is not surprising since it is known that the undissolved second phase particles can effectively prevent significant grain coarsening, leading to a Zener limiting grain size [5]. The starting microstructures of the three variants are thus considered as the same in the following discussion.

In terms of microchemistry, the SEM micrographs showing the particle distribution of the three variants after homogenization (before deformation) are presented in Ref [3]. However, the key measured quantities and microchemistry parameters of the as-cast (C1-0) and the as-homogenized conditions (C1-2 and C1-3) are summarized in Table 1. The concentration of $\mathrm{Mn}$ in the matrix was estimated based on the relationship between electrical conductivity and concentration of alloying elements in solid solution, the details of which can be found elsewhere 

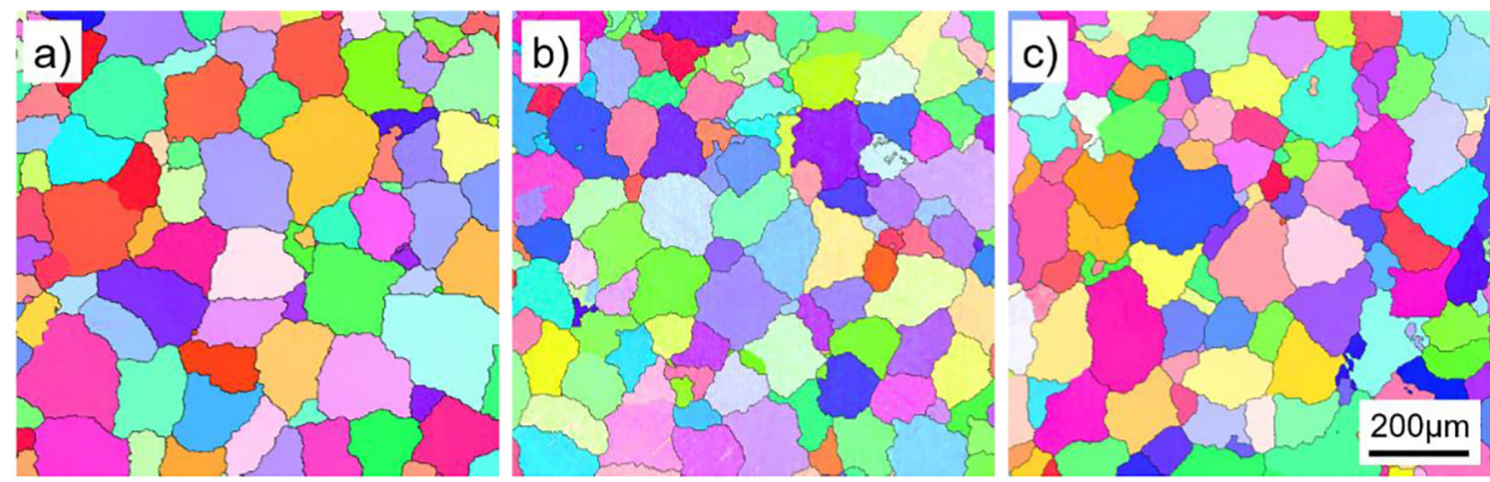

Fig. 1. SEM-EBSD Orientation imaging micrographs of the microstructure of the three variants. a) C1-0 [3]; b) C1-2; c) C1-3.

[22].

Since the starting microstructure of the three variants are similar, only the microstructures of the C1-3 variant deformed to different strains are shown in Fig. 2. When the sample is deformed to $\varepsilon=0.7$, the original equiaxed grains (see Fig. 1) are somewhat flattened, but the grain boundaries have not yet been fully aligned with the RD direction, as shown in Fig. 2a. At the larger strain of $\varepsilon=1.6$, the deformed microstructure is characterized by pancake-shaped coarse elongated grains and most of the old grain boundaries are now parallel to the RD direction (Fig. 2b). With the largest strain of $\varepsilon=3.0$, it is evident that the distance between the high-angle grain boundaries of the deformed grains is much smaller than that of the sample deformed to $\varepsilon=1.6$, as can be seen in Fig. 2c. The subgrain structures after this deformation can be seen in Fig. 3, all of them are elongated along the RD direction. In terms of the distribution of dispersoids formed during homogenization, no dispersoids are visible for the as-cast variant of C1-0, but large number of evenly distributed fine dispersoids are present for C1-2 while only a small number of coarser dispersoids are present for C1-3.

\subsection{The effect of cold deformation and microchemistry on the recrystallization kinetics and concurrent precipitation}

The evolution of hardness is indirectly used to study the recrystallization kinetics in this work. The recrystallization kinetics can be evaluated by the onset and completion time of recrystallization, the former is reflected by the time when fast decreasing of hardness value occurs while the latter is the time when the steady state hardness is first reached. As can be seen in Fig. 4a, c and e, the initial hardness of the samples increases with deformation level for all the three variants. Meanwhile, for the samples deformed to the same deformation level, the hardness values of the C1-0 samples are always the highest and C1-3 samples are always the lowest. It is also clear from Fig. 4a, c and e that recrystallization is always faster for the sample with higher deformation level. This is logical since larger deformation leads to more stored energy which provides the driving force for recrystallization. The same tendency can be observed when the precipitation potential (C1$0>$ C1-2 > C1-3) decreases, i.e., lower concentration level of Mn. It should be noted that even though recrystallization could complete within 10 s for some samples, annealing at $400{ }^{\circ} \mathrm{C}$ for $10^{5} \mathrm{~s}$ is not enough to fully recrystallize the $\mathrm{C} 1-0$ and $\mathrm{C} 1-2$ samples deformed to $\varepsilon=0.7$.

The variation of electrical conductivity is used to monitor the concurrent precipitation during isothermal annealing. As illustrated in Fig. $4 \mathrm{~b}, \mathrm{~d}$ and $\mathrm{f}$, the initial EC values of the three variants are quite different, with C1-0 being the lowest and C1-3 being the highest. The increase of EC during annealing is most significant for the C1-0 samples, reflecting its strong concurrent precipitation behaviour. Only slight increase of EC is observed for the C1-3 samples, suggesting a very weak concurrent precipitation for this category of samples. Larger deformations are believed to accelerate concurrent precipitation since the accumulated dislocation density is usually higher and these dislocations serve as potential nucleation sites for precipitates. However, large deformations also promote faster recrystallization, which leads to an almost dislocation-free structure and conversely delay the concurrent precipitation. Therefore, it is interesting to notice that the concurrent precipitation kinetics is not linearly correlated to cold deformation level. For instance, as shown in Fig. 4b, the increase of EC is indeed faster for the sample with the highest deformation before 1000s, after which the increase of EC is inversely correlated to the cold deformation level, i.e., the sample with the smallest deformation $(\varepsilon=0.7)$ has the fastest concurrent precipitation.

\subsection{The effect of cold deformation on the microstructure evolution}

\subsubsection{The microstructure evolution of $\mathrm{C1}-\mathrm{O}$}

The microstructure evolution of the as-cast variant, which has the highest potential for concurrent precipitation, was first examined. As shown in Fig. 5, recrystallization has not been activated yet for the samples annealed at the lowest temperature of $300{ }^{\circ} \mathrm{C}$, regardless of the prior deformation strain (see Fig. 5a, d and g). Elongated grain structures are observed for the samples annealed at $400{ }^{\circ} \mathrm{C}$, the recrystallized fractions increase and recrystallized grain sizes decrease with increasing prior deformation strain, as shown in Fig. 5b, e and h. When the samples were annealed at $500{ }^{\circ} \mathrm{C}$, the deformation matrix are all fully replaced by the equiaxed recrystallized grains, and the recrystallized grain size is found to decrease with cold rolling deformation strains (Fig. 5c, f and i). It appears that a variety of microstructures, with grain sizes ranging from 21 to $116 \mu \mathrm{m}$, can already be obtained using samples with the same microchemistry but with varying

Table 1

The EC, solute levels, diameter and number density of particles [19] in the as-cast and as-homogenized conditions.

\begin{tabular}{|c|c|c|c|c|c|c|}
\hline & $\begin{array}{l}\text { Electrical conductivity } \\
\left(\mathrm{m} / \Omega \mathrm{mm}^{2}\right)\end{array}$ & $\begin{array}{l}\text { Concentration of } \mathrm{Mn} \\
(\mathrm{wt} \%)\end{array}$ & $\begin{array}{l}\text { Diameter } \\
(\mu \mathrm{m})\end{array}$ & $\begin{array}{l}\text { Number density } \\
\left(\mathrm{mm}^{-2}\right)\end{array}$ & $\begin{array}{l}\text { Diameter } \\
(\mu \mathrm{m})\end{array}$ & $\begin{array}{l}\text { Number density } \\
\left(\mathrm{mm}^{-2}\right)\end{array}$ \\
\hline C1-0 & 23.9 & 0.35 & 0.88 & $2.8 \mathrm{e} 4$ & - & - \\
\hline C1-2 & 27.5 & 0.16 & 0.96 & $2.9 \mathrm{e} 4$ & 0.054 & $1.3 \mathrm{e} 6$ \\
\hline C1-3 & 29.0 & 0.11 & 1.10 & $2.1 \mathrm{e} 4$ & 0.127 & $5.5 \mathrm{e} 4$ \\
\hline
\end{tabular}



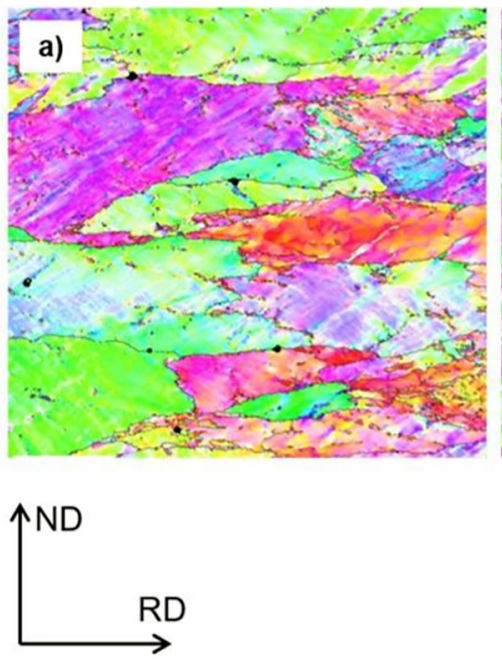
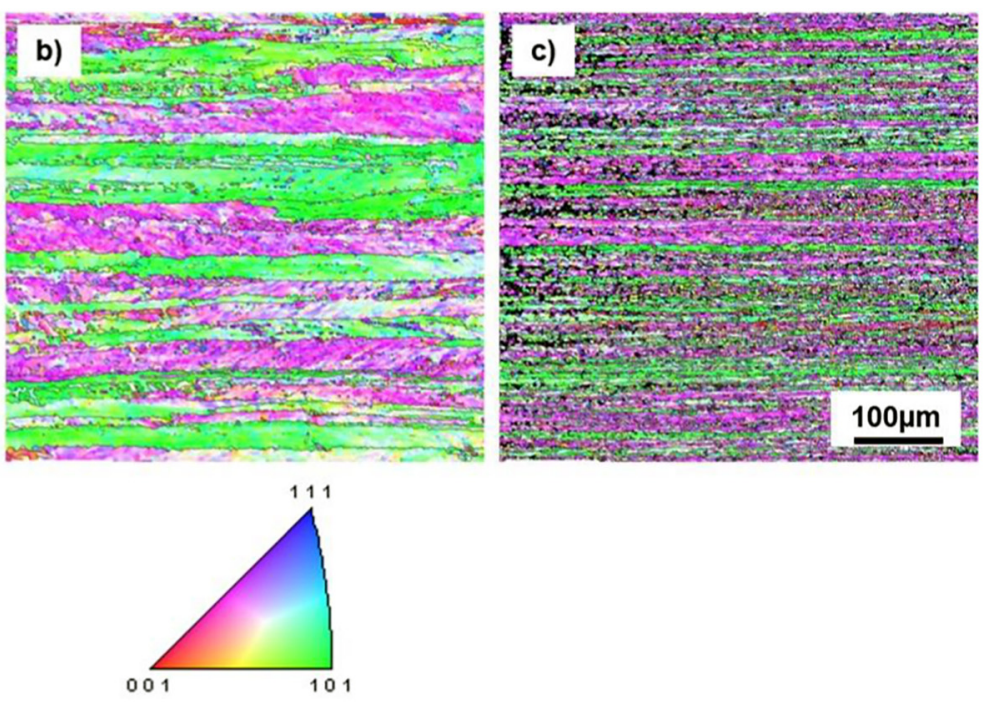

Fig. 2. SEM-EBSD Orientation imaging micrographs of the microstructure after deformation of C1-3 [22]. a) $\varepsilon=0.7$; b) $\varepsilon=1.6$; c) $\varepsilon=3.0$.

deformation strain and annealing temperature.

\subsubsection{The microstructure evolution of $\mathrm{C1-2}$}

When the as-cast materials were heated at $50{ }^{\circ} \mathrm{C} / \mathrm{h}$ to $450{ }^{\circ} \mathrm{C}$ and kept for $4 \mathrm{~h}$, a large number of fine dispersoids were formed, and the solute concentration of $\mathrm{Mn}$ decreased from $0.35 \%$ to $0.16 \%$, as listed in Table 1. As compared to C1-0 samples, these pre-existing dispersoids and the decreased concurrent precipitation tendency are expected to bring a different microstructure evolution of the C1-2 samples. Indeed, recrystallization has initiated when annealed at $300{ }^{\circ} \mathrm{C}$ for the sample deformed to $\varepsilon=3.0$ (see Fig. $6 \mathrm{~g}$ ). Increasing the annealing temperature to $400{ }^{\circ} \mathrm{C}$ obviously leads to faster recrystallization, but full recrystallization has not been reached yet for the sample deformed to $\varepsilon=0.7$ (see Fig. 6b), a fully recrystallized grain structure is eventually observed when it was annealed at $500{ }^{\circ} \mathrm{C}$ (see Fig. 6c). The recrystallized grain structures at $500{ }^{\circ} \mathrm{C}$ are slightly elongated even for the samples deformed to $\varepsilon=3.0$, as illustrated in Fig. 6i. A close look at Fig. $6 \mathrm{~h}$ and i reveals that increasing annealing temperature from $400{ }^{\circ} \mathrm{C}$ to $500{ }^{\circ} \mathrm{C}$ does not further refine the grain structure. For this variant, the recrystallized grain sizes are within $23-65 \mu \mathrm{m}$.

\subsubsection{The microstructure evolution of C1-3}

For the variant C1-3, which has the lowest concentration level of Mn and only a limited number density of relatively coarse dispersoids (see Table 1), recrystallization is much faster than the previous two variants. Only a few non-recrystallized grains (pointed out by black arrows) are visible even for the sample deformed to $\varepsilon=0.7$ and annealed at $300{ }^{\circ} \mathrm{C}$, as shown in Fig. 7a. Except for the $\varepsilon=0.7$ samples, which have quite inhomogeneous grain structures (in terms of grain size), the recrystallized grain structures are mainly equiaxed, regardless of the annealing temperature and prior deformation strain. For the samples annealed at the same temperature, increasing the deformation strain obviously decreases the recrystallized grain size. However, for the samples deformed to the same strain, increasing the annealing temperature does not necessarily guarantee finer recrystallized grain size, see e.g. Fig. $7 \mathrm{~g}, \mathrm{~h}$ and i. This is because slight grain growth is expected after the recrystallization process when the samples are soaked (for a long time $\left(10^{5} \mathrm{~s}\right)$ ) at the high temperature of $500{ }^{\circ} \mathrm{C}$. Equiaxed grain structures with grain sizes ranging from 22 to 38 are obtained for this variant.

\section{Discussion}

\subsection{Interaction between precipitates and recrystallization}

Even though the samples deformed to different strain levels of the three variants have been isothermally annealed at three different temperatures, only the samples annealed at $400{ }^{\circ} \mathrm{C}$ are present in Fig. 4. It was shown in Figs. 5-7 that the effects of cold deformation and microchemistry on the recrystallization kinetics and concurrent precipitation are clearly demonstrated at this temperature, while sluggish recrystallization dominates at $300{ }^{\circ} \mathrm{C}$ and recrystallization completes too fast at $500{ }^{\circ} \mathrm{C}$ [3]. The effect of prior deformation strain on the recrystallization kinetics is clearly shown for the C1-0 and C1-2 samples (see Fig. 4a and c) while recrystallization completes quite fast for all deformations for the C1-3 sample in Fig. 3e. With respect to the effect of microchemistry, C1-3 samples obviously have the fastest recrystallization kinetics since recrystallization completes within $100 \mathrm{~s}$ at $400{ }^{\circ} \mathrm{C}$ for
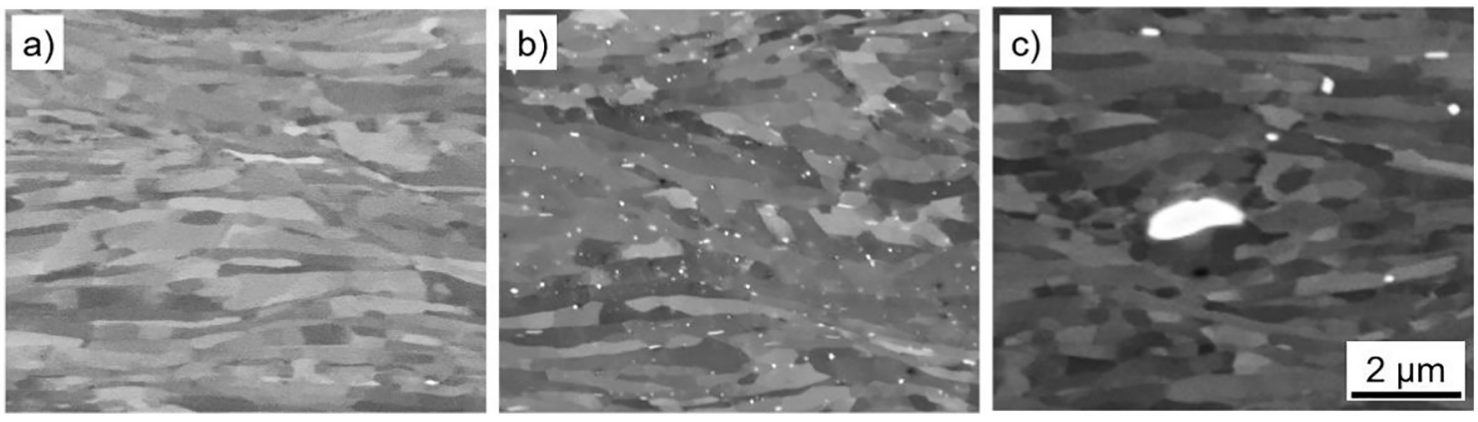

Fig. 3. SEM-BSE micrographs indicating the presence, size and distribution of dispersoids after cold rolling to $\varepsilon=3.0$. a) C1-0; b) C1-2; c) C1-3. 

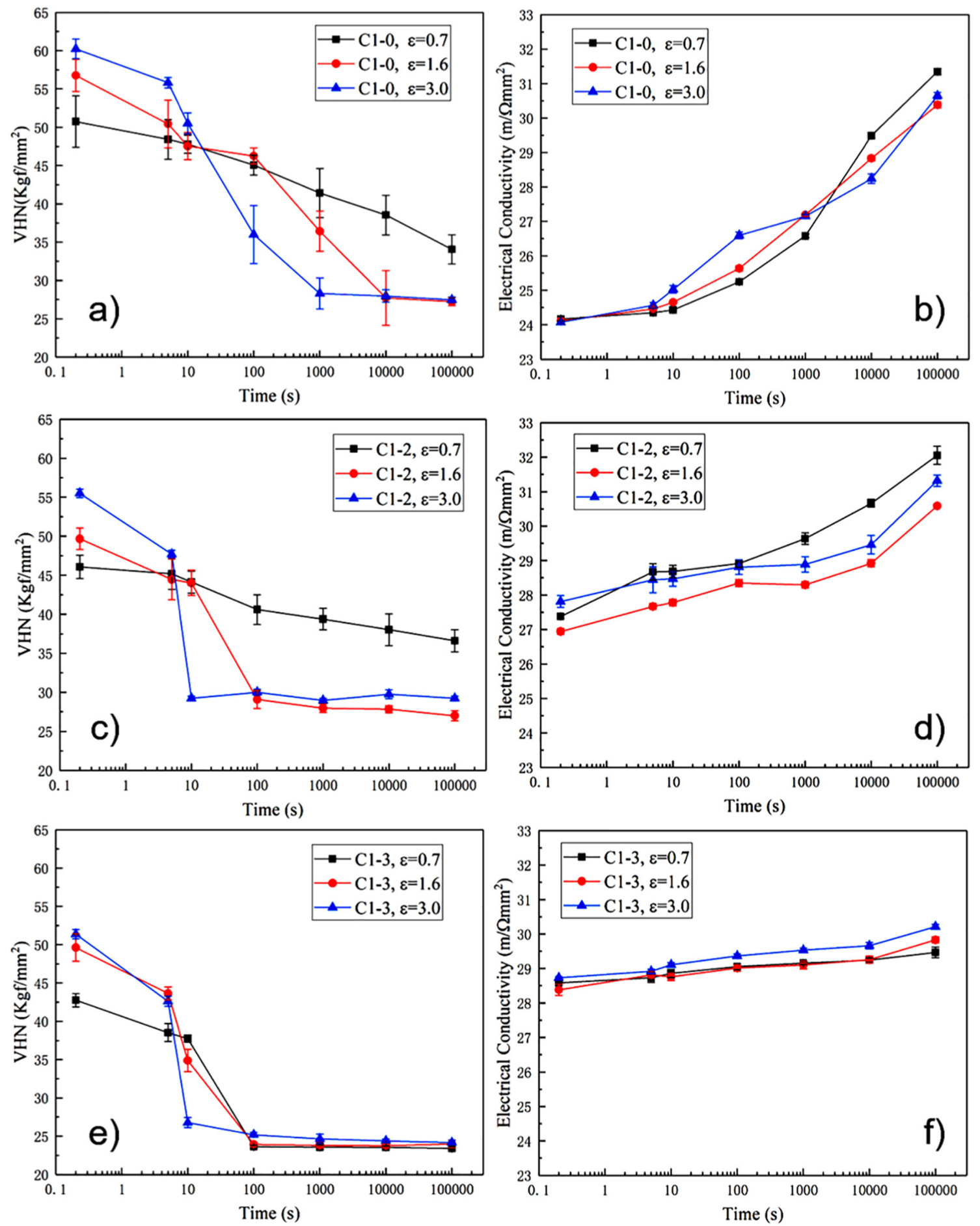

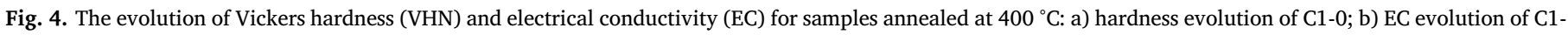
0; c) hardness evolution of C1-2; d) EC evolution of C1-2; e) hardness evolution of C1-3; f) EC evolution of C1-3.

the sample deformed to $\varepsilon=0.7$ while full recrystallization was not yet reached after annealing for $10^{5} \mathrm{~s}$ at the same temperature for the other two variants. The fact that the recrystallization kinetics of the C1-2 samples is faster than that of the C1-0 samples is obvious since it takes $100 \mathrm{~s}$ for the former variant while $10,000 \mathrm{~s}$ are needed for the latter one to reach complete recrystallization after deformation to $\varepsilon=1.6$.

For the samples of the three variants deformed to the same strain level and annealed at the same temperature, the variation in recrystallization kinetics is related to their variation in microchemistry. As shown in Fig. 4b, d, f, concurrent precipitation is most significant for the C1-0 samples, followed by the C1-2 samples and then the C1-3 samples. This explains why the recrystallization kinetics takes the opposite order, i.e., C1-3 > C1-2 > C1-0. Firstly, if the recrystallization kinetics is so fast that it completes before substantial concurrent precipitation takes place, only the pre-existing dispersoids listed in Table 1 affect the recrystallization process, which is the case for the C1-2 and C1-3 samples deformed to $\varepsilon=3.0$ and annealed at $400{ }^{\circ} \mathrm{C}$ (see Figs. $6 \mathrm{~h}$ and $7 \mathrm{~h}$ ) where recrystallization completes within 10 s for both samples during which significant EC increase has not initiated. The recrystallized grains in the $\mathrm{C} 1-2$ sample, which has more and finer pre- 

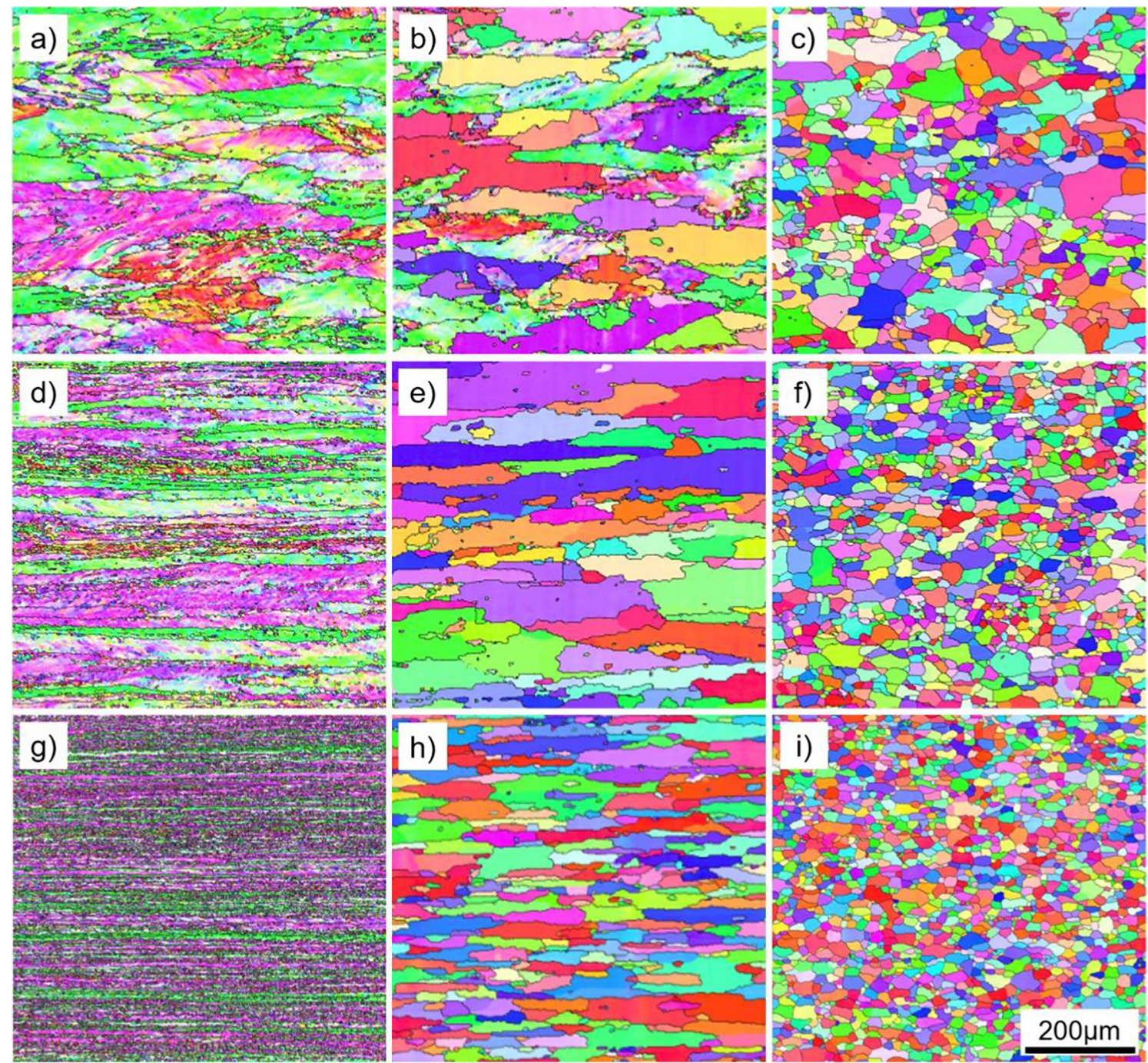

Fig. 5. SEM-EBSD orientation imaging micrographs for C1-0, annealed for $10^{5} \mathrm{~s}$.

a) $\varepsilon=0.7,300{ }^{\circ} \mathrm{C}$; b) $\varepsilon=0.7,400{ }^{\circ} \mathrm{C}$; c) $\left.\left.\left.\left.\varepsilon=0.7,500{ }^{\circ} \mathrm{C}\left(\mathrm{d}_{\mathrm{Av}}=44 \mu \mathrm{m}\right) ; \mathrm{d}\right) \varepsilon=1.6,300{ }^{\circ} \mathrm{C} ; \mathrm{e}\right) \varepsilon=1.6,400{ }^{\circ} \mathrm{C}\left(\mathrm{d}_{\mathrm{Av}}=116 \mu \mathrm{m}\right) ; \mathrm{f}\right) \varepsilon=1.6,500{ }^{\circ} \mathrm{C}\left(\mathrm{d}_{\mathrm{Av}}=28 \mu \mathrm{m}\right) ; \mathrm{g}\right)$ $\varepsilon=3.0, T=300{ }^{\circ} \mathrm{C}$; h $) \varepsilon=3.0, T=400{ }^{\circ} \mathrm{C}\left(\mathrm{d}_{\mathrm{Av}}=56 \mu \mathrm{m}\right)$ [3]; i) $\varepsilon=3.0, T=500{ }^{\circ} \mathrm{C}\left(\mathrm{d}_{\mathrm{Av}}=21 \mu \mathrm{m}\right)[3]$.

existing dispersoids, are slightly elongated while a perfect equiaxed grain structure is obtained for the C1-3 samples. Secondly, if dispersoids are precipitated before recrystallization, they not only suppress nucleation but also pin the migration of grain boundaries if recrystallization does take place. Good examples are the C1-0 and C1-2 samples annealed at $300{ }^{\circ} \mathrm{C}$, while the $\mathrm{C} 1-3$ sample recrystallize at this temperature since it has limited potential for precipitation (cf. Figs. 5-7). Between the first and second cases, we have the last situation where recrystallization and precipitation take place concurrently, the samples deformed to $\varepsilon=1.6$ belong to this category. Obviously, variants with stronger concurrent precipitation exhibits higher Zener pinning effects on grain boundary migration, which leads to slower recrystallization kinetics.

The direct evidence of the interaction between precipitation and recrystallization is now further examined by looking at the early recrystallization of the samples deformed to $\varepsilon=1.6$ and then annealed at $400{ }^{\circ} \mathrm{C}$. As illustrated in Fig. 8a, no evident dispersoids are formed for the C1-0 variant after the short annealing time of $5 \mathrm{~s}$. However, after $10 \mathrm{~s}$ of annealing, fine dispersoids have clearly precipitated along the subgrain boundaries, caused by the significant precipitation potential of the C1-0 variant. These fine dispersoids impede the migration of subgrain boundaries, making it difficult for the subgrains to reach critical nucleus size [23], which is typically a few microns in size, and recrystallization is thus clearly retarded for C1-0. For the C1-2 sample, which has a weaker precipitation potential than $\mathrm{C} 1-0$, the dispersoids seen within the subgrains (see Fig. 8c) must be the pre-existing ones from before annealing since no precipitation is expected during the first $5 \mathrm{~s}$ annealing. Annealing for $10 \mathrm{~s}$ leads to a higher total number density of dispersoids than C1-0 (compare Fig. 8b and d), but recrystallization (as pointed out by black arrow) has actually started here since the majority of dispersoids, which are the pre-existing ones within subgrains (as pointed out by white arrows), exert a limited Zener pinning on the migration of subgrain boundaries. Recrystallization started within 5 s (see Fig. 8e) for the C1-3 samples through, most likely, particle stimulated nucleation (PSN) [5,24]. It is recalled here that among the three variants, the average constituent particle size of C1-3 is the largest, and it is beyond the typical critical size $(>1 \mu \mathrm{m})$ to trigger PSN in aluminium alloys [5]. Annealing for a longer time of 10 s leads to a substantial recrystallization fraction, and only limited number of preexisting and concurrent precipitates are observed (Fig. 8f).

\subsection{Grain structure}

By varying the homogenization procedures and prior cold deformation strains, distinctly different grain structures were formed after annealing at different conditions. The deformation structures of the C1- 

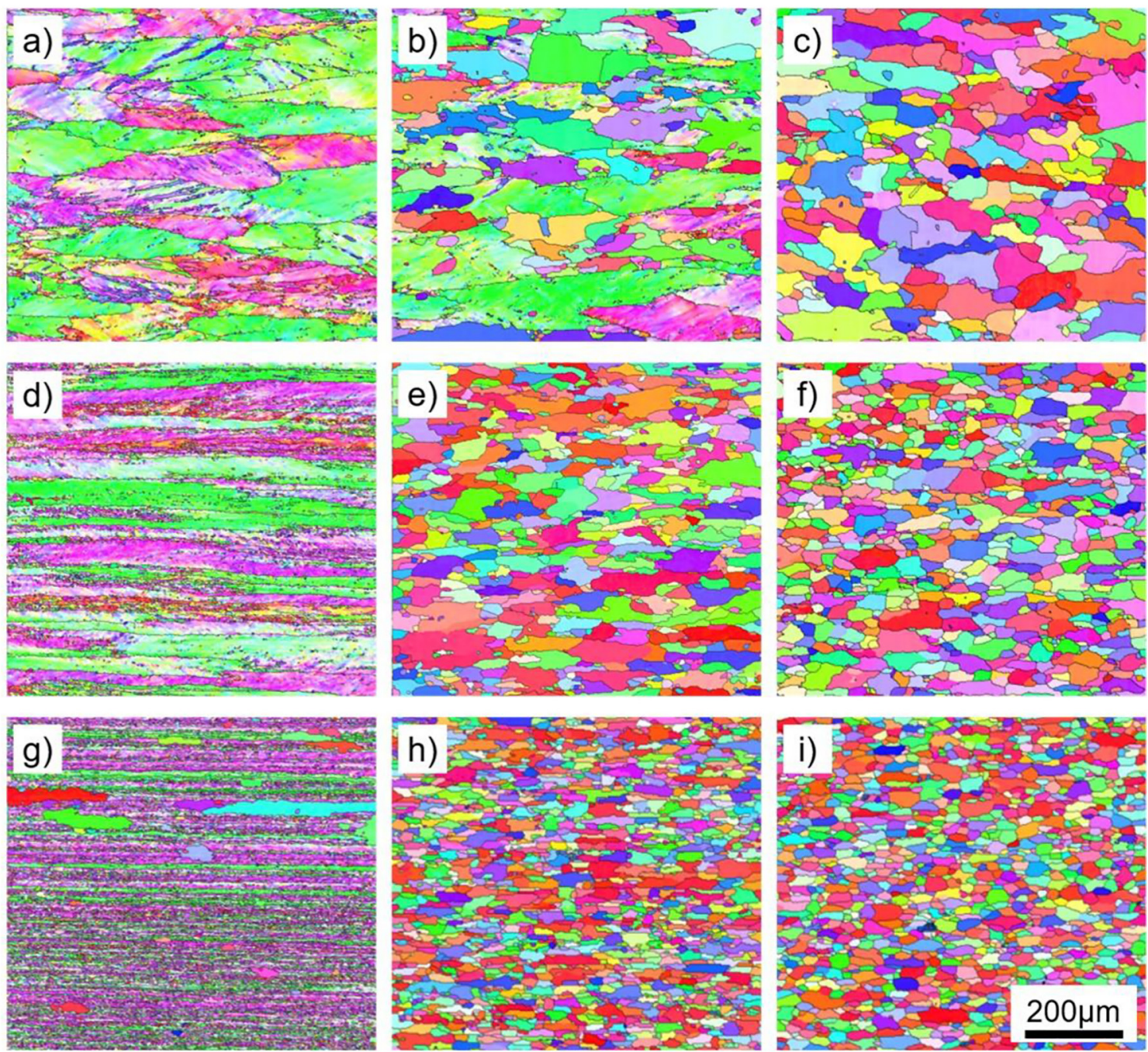

Fig. 6. SEM-EBSD Orientation imaging micrographs for C1-2, annealed for $10^{5} \mathrm{~s}$.

a) $\varepsilon=0.7,300{ }^{\circ} \mathrm{C}$; b) $\varepsilon=0.7,400{ }^{\circ} \mathrm{C}$; c) $\left.\varepsilon=0.7,500{ }^{\circ} \mathrm{C}\left(\mathrm{d}_{\mathrm{Av}}=65 \mu \mathrm{m}\right) ; \mathrm{d}\right) \varepsilon=1.6,300{ }^{\circ} \mathrm{C}$; e) $\left.\left.\varepsilon=1.6,400{ }^{\circ} \mathrm{C}\left(\mathrm{d}_{\mathrm{Av}}=43 \mu \mathrm{m}\right) ; \mathrm{f}\right) \varepsilon=1.6,500{ }^{\circ} \mathrm{C}\left(\mathrm{d}_{\mathrm{Av}}=33 \mu \mathrm{m}\right) ; \mathrm{g}\right)$ $\varepsilon=3.0, T=300{ }^{\circ} \mathrm{C}$; h $) \varepsilon=3.0, T=400{ }^{\circ} \mathrm{C}\left(\mathrm{d}_{\mathrm{Av}}=24 \mu \mathrm{m}\right)$ [3]; i) $\varepsilon=3.0, T=500{ }^{\circ} \mathrm{C}\left(\mathrm{d}_{\mathrm{Av}}=23 \mu \mathrm{m}\right)[3]$.

0 samples are found to be quite stable up to $300{ }^{\circ} \mathrm{C}$ (see Fig. 5) since no onset of recrystallization is reached yet. Components fabricated under the same conditions can thus be used in conditions where both high strength and thermal stability are required. In fact, a similar situation is found for the C1-2 samples annealed at $300{ }^{\circ} \mathrm{C}$ except that a coarse and strongly elongated microstructure is expected for the samples deformed to $\varepsilon=3.0$ if longer annealing times are imposed (see Fig. 6). A coarse grain structure is generally preferred for fabricating heat exchangers for the automobile industry due to their superior corrosion resistance, good brazeability and high sagging resistance [4]. It should also be noted that annealing the $\mathrm{C} 1-0$ samples at $400{ }^{\circ} \mathrm{C}$ leads to coarse grain structures, regardless of the prior deformation strains. For more details on the gradual evolution of microstructures, the reader is referred to Ref [25]. Except perhaps for the lowest strain, nearly equiaxed fine grain structures (below $40 \mu \mathrm{m}$ ) with different average grain sizes are observed for the C1-3 samples at all conditions, as illustrated in Fig. 7. Fine grain structures can also be obtained for the C1-0 and C1-2 samples annealed at $500{ }^{\circ} \mathrm{C}$ even though both of which still have potential to precipitate fine dispersoids (see Table 1 ) and thus are subjected to sluggish recrystallization. However, at this high temperature, recrystallization completes before substantial precipitation takes place. On the other hand, the precipitated dispersoids after recrystallization exert a Zener pinning on the formed grain boundaries and will effectively limit further coarsening of the recrystallized grains. A fine grain size is preferred for products that require good formability and surface quality, e.g., beverage can bodies.

The reason behind the formation of coarse elongated grain structures requires further explanation. It can be seen from Fig. $6 \mathrm{~g}$ that the microstructure of the C1-2 sample deformed to $\varepsilon=3.0$ and annealed at $300{ }^{\circ} \mathrm{C}$ for $10^{5} \mathrm{~s}$ exhibits few very elongated recrystallized grains. The sample has not been fully recrystallized, but it provides the best opportunity to investigate why an elongated grain structure is formed. As shown in Fig. 9a, the deformation structure is kept for the majority of the sample, and the constituent particles are aligned along the RD direction. The reason why the extent of recrystallization is still limited even after such a long annealing time can be understood from the enlarged SEM micrograph shown in Fig. 9b, where it can be seen that most of the subgrain boundaries are pinned by the fine precipitates. Only a few subgrains are able to develop into viable recrystallization nuclei (see Fig. 9c), and these nuclei will be able to grow to large recrystallized grains, since their probability to impinge with other already recrystallized grains are low. This explains why coarse grains can be formed. On the other hand, the elongated recrystallized grains shown in Fig. 9c show limited growth in the ND direction, it seems their growth are stopped by the aligned constituent particles, as pointed out by the black arrows. Assuming spherical and randomly distributed second phase particles, the classical expression for Zener pinning pressure $\left(\mathrm{P}_{\mathrm{Z}}\right)$ is given by the following expression [26,27]: 

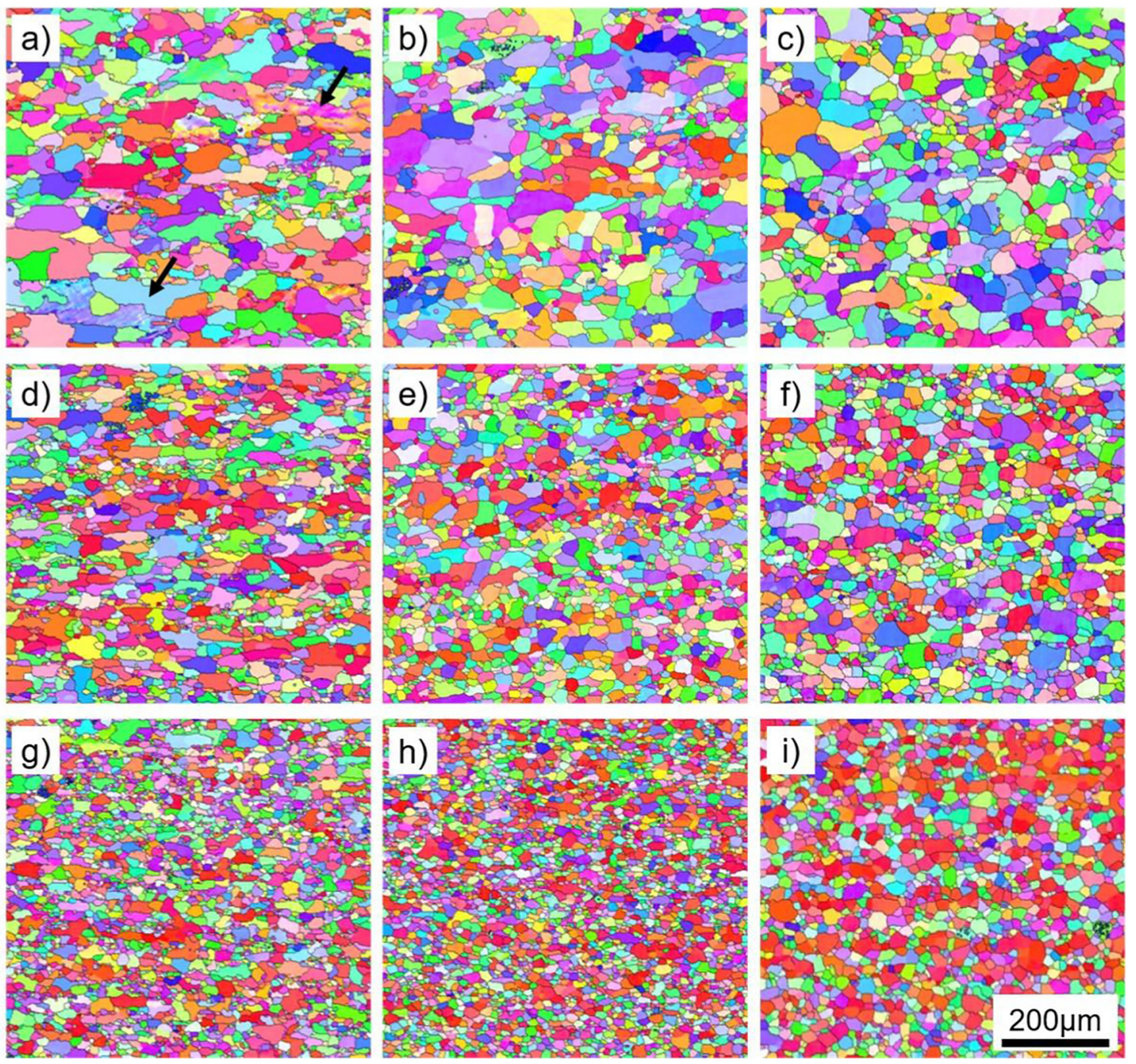

Fig. 7. SEM-EBSD orientation imaging micrographs for C1-3, annealed for $10^{5} \mathrm{~s}$.

a) $\varepsilon=0.7,300{ }^{\circ} \mathrm{C}$; b) $\left.\left.\left.\varepsilon=0.7,400{ }^{\circ} \mathrm{C}\left(\mathrm{d}_{\mathrm{Av}}=38 \mu \mathrm{m}\right) ; \mathrm{c}\right) \varepsilon=0.7,500{ }^{\circ} \mathrm{C}\left(\mathrm{d}_{\mathrm{Av}}=38 \mu \mathrm{m}\right) ; \mathrm{d}\right) \varepsilon=1.6,300{ }^{\circ} \mathrm{C}\left(\mathrm{d}_{\mathrm{Av}}=26 \mu \mathrm{m}\right) ; \mathrm{e}\right) \varepsilon=1.6,400{ }^{\circ} \mathrm{C}\left(\mathrm{d}_{\mathrm{Av}}=24 \mu \mathrm{m}\right)$; $)$ $\left.\left.\left.\varepsilon=1.6,500{ }^{\circ} \mathrm{C}\left(\mathrm{d}_{\mathrm{Av}}=26 \mu \mathrm{m}\right) ; \mathrm{g}\right) \varepsilon=3.0, T=300{ }^{\circ} \mathrm{C}\left(\mathrm{d}_{\mathrm{Av}}=20 \mu \mathrm{m}\right)[3] ; \mathrm{h}\right) \varepsilon=3.0, T=400{ }^{\circ} \mathrm{C}\left(\mathrm{d}_{\mathrm{Av}}=16 \mu \mathrm{m}\right)[3] ; \mathrm{i}\right) \varepsilon=3.0, T=500{ }^{\circ} \mathrm{C}\left(\mathrm{d}_{\mathrm{Av}}=22 \mu \mathrm{m}\right)$.

$\mathrm{P}_{Z}=\frac{3 \gamma f}{2 r}$

where $P_{\mathrm{Z}}$ is dependent on the subgrain boundary energy $(\gamma)$, volume fraction $(f)$ and average size $(r)$ of the particles. Although the constituent particles also provide a pinning effect, their size $(\sim 0.88 \mu \mathrm{m})$ is much larger than that of the fine precipitates $(\sim 50 \mathrm{~nm})$, and according to Eq. (1) their contribution to the pinning pressure is thus expected to be small. However, given the fact that they are concentrated in layers (aligned with $\mathrm{RD}$ ) and probably mainly on the original grain boundaries, which after cold rolling are aligned along $\mathrm{RD}$, their pinning effect might be significantly stronger than Eq. (1) indicates [27], which is based on the assumption of a random spatial distribution of particles. It should be noted that this is not expected to be the main/sole reason for the limited growth in the ND-direction. In fact, an equiaxed grain structure was obtained for the C1-3 variant subjected to the same heat treatment condition (see Fig. $7 \mathrm{~g}$ ) and which is expected to have the same constituent particle structure as C1-2. However, in contrast to the C1-3 variant, C1-2 also experiences some concurrent precipitation, which will also primarily take place on high angle grain boundaries $[4,14]$ and contribute to a more effective pinning pressure in the ND direction than for lateral growth. But this is not 'black or white', even for the C1-2 sample, the grain pointed out by white arrow in Fig. 9d is also able to break away from the constituent particles.

Another possible reason that these grains do not grow equally well in the ND direction can be related to "orientation pinning" [28]. After cold rolling, the original grains of different orientations are elongated along $\mathrm{RD}$, the recrystallized grains will preferentially grow at the expense of certain deformed grains if special grain boundaries can be formed between them [29-34]. It has been reported that some special grain boundaries with relatively low boundary energy enjoy both higher migration rate and less precipitates [4,11,14]. Preferential growth along ND will be terminated (or strongly retarded) if their moving boundaries meet non-favourable orientations which are typically elongated along RD. That is probably why the grain boundary pointed out by white arrow in Fig. $9 \mathrm{~d}$ is in general aligned along RD, even though local protrusions and retrusions still appear.

\subsection{Crystallographic texture}

Appropriate crystallographic texture is important for aluminium alloys, especially for their sheet products that need to be further deformed during different forming operations. Crystallographic textures inevitably develop during thermo-mechanical processing, where characteristic deformation textures result from the deformation process (e.g. rolling or extrusion), and recrystallization textures are obtained upon 

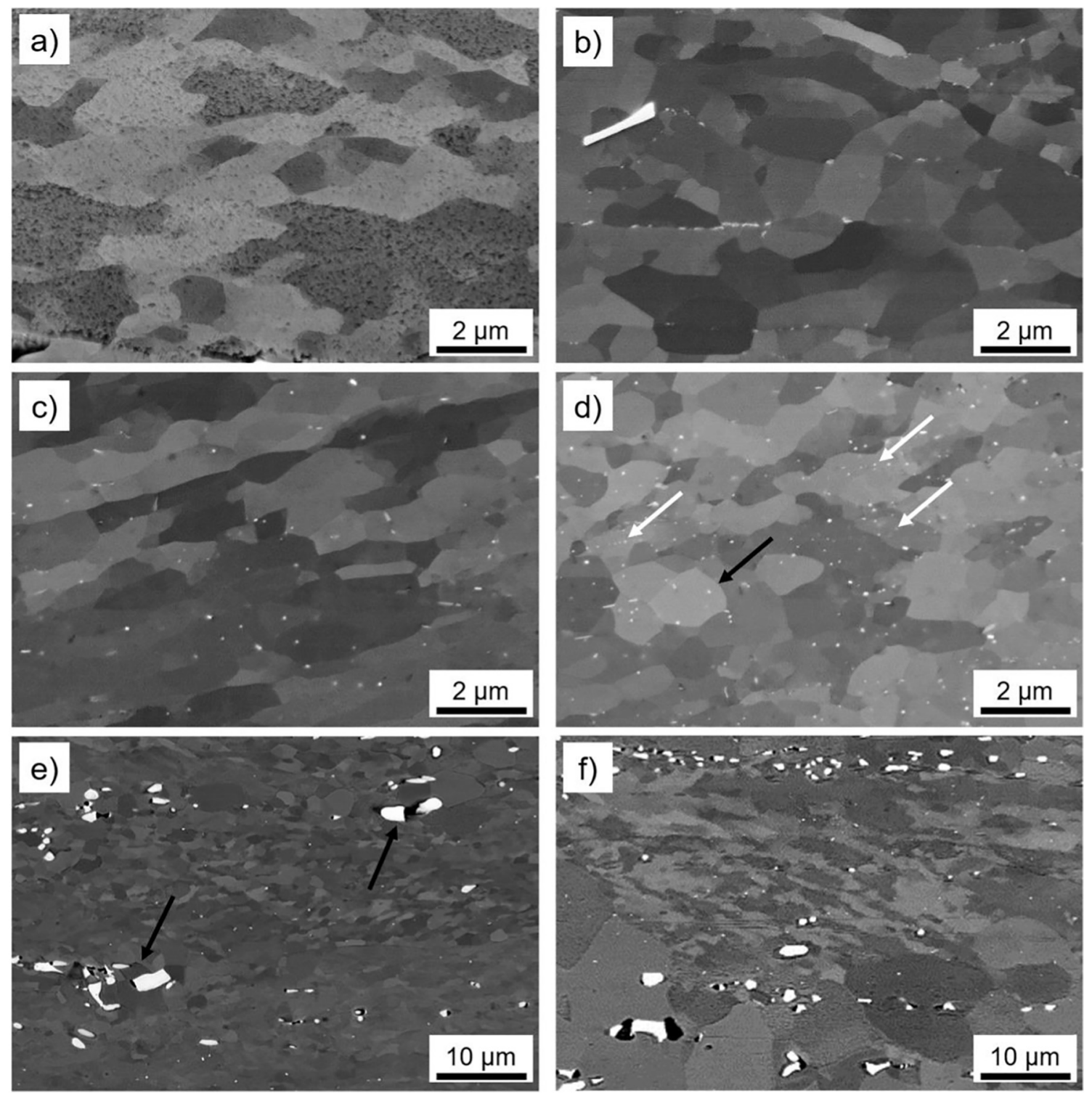

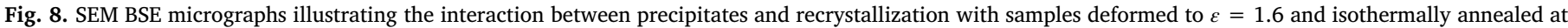
$400{ }^{\circ} \mathrm{C}$. a) C1-0, $5 \mathrm{~s}$; b) C1-0, $10 \mathrm{~s}$; c) C1-2, $5 \mathrm{~s}$; d) C1-2, $10 \mathrm{~s}$; e) C1-3, $5 \mathrm{~s}$; f) C1-3, $10 \mathrm{~s}$.

annealing and recrystallization, both of which bring important consequences for the properties. A notable example is the phenomenon of earing, which is a troublesome feature related to crystallographic texture and is often observed during the deep drawing of rolled aluminium sheets. Investigations on the formation mechanisms of different texture components, cube texture in particular, is intimately connected to and have significantly advanced our current knowledge on the recrystallization theory. Due to its industrial and academic relevance, significant efforts have been invested in quantitative texture and anisotropy engineering through inverse texture simulation methods [35]. The ultimate goal is being able to quantitatively tailor the textures to match the desired final anisotropy. The space limit of the paper, however, does not allow us to discuss in detail all the textures corresponding to the microstructures obtained at different conditions as presented in Figs. 5-7, even though these data can be easily accessed with the EBSD data. The feasibility to tailor the crystallographic texture, using the same starting materials, through the combination of varying homogenization procedure and prior cold deformation is thus only briefly discussed here.

In many applications, it is desirable for the final products to have isotropic materials with evenly distributed grain orientations in order to have isotropic properties during their operation service. The texture of the C1-0 sample deformed to $\varepsilon=0.7$ and annealed at $500{ }^{\circ} \mathrm{C}$ for $10^{5} \mathrm{~s}$, with the corresponding equiaxed grain structure shown in Fig. 5c, has a texture intensity of only 2.8 , this sample can be thus be considered as close to isotropic, in view of the fact that a complete random texture is rarely observed in structural materials. It should be noted that the deformation texture after the moderate deformation of $\varepsilon=0.7$ is quite weak, a large number of different orientations are thus equally probable for nucleation at the high temperature of $500{ }^{\circ} \mathrm{C}$. The growth of these nuclei suffers little from second phase particles, it is thus not surprising that a close to random texture is also obtained after recrystallization.

However, random starting textures do not necessarily remain weak when a material is subsequently subjected to significant plastic deformation. For instance, cold rolling of aluminium alloys is known to produce deformation textures, which is primarily composed of the $\mathrm{S}$ orientation, $\left\{\begin{array}{lll}1 & 2 & 3\end{array}\right\}\langle 634\rangle$, the Brass orientation, $\left\{\begin{array}{lll}1 & 1 & 0\end{array}\right\}\langle 112\rangle$, and the Copper orientation $\left\{\begin{array}{lll}1 & 1 & 2\end{array}\right\}\langle 111\rangle$ [5]. These texture components promote earing essentially at $45^{\circ} / 135^{\circ}$ with respect to the rolling direction during subsequent deep drawing process [5]. It is thus desirable to have non-random starting textures to compensate the earing formed due to the starting deformation textures. In practice, cube orientation, $\left\{\begin{array}{lll}1 & 0 & 0\end{array}\right\}$ 

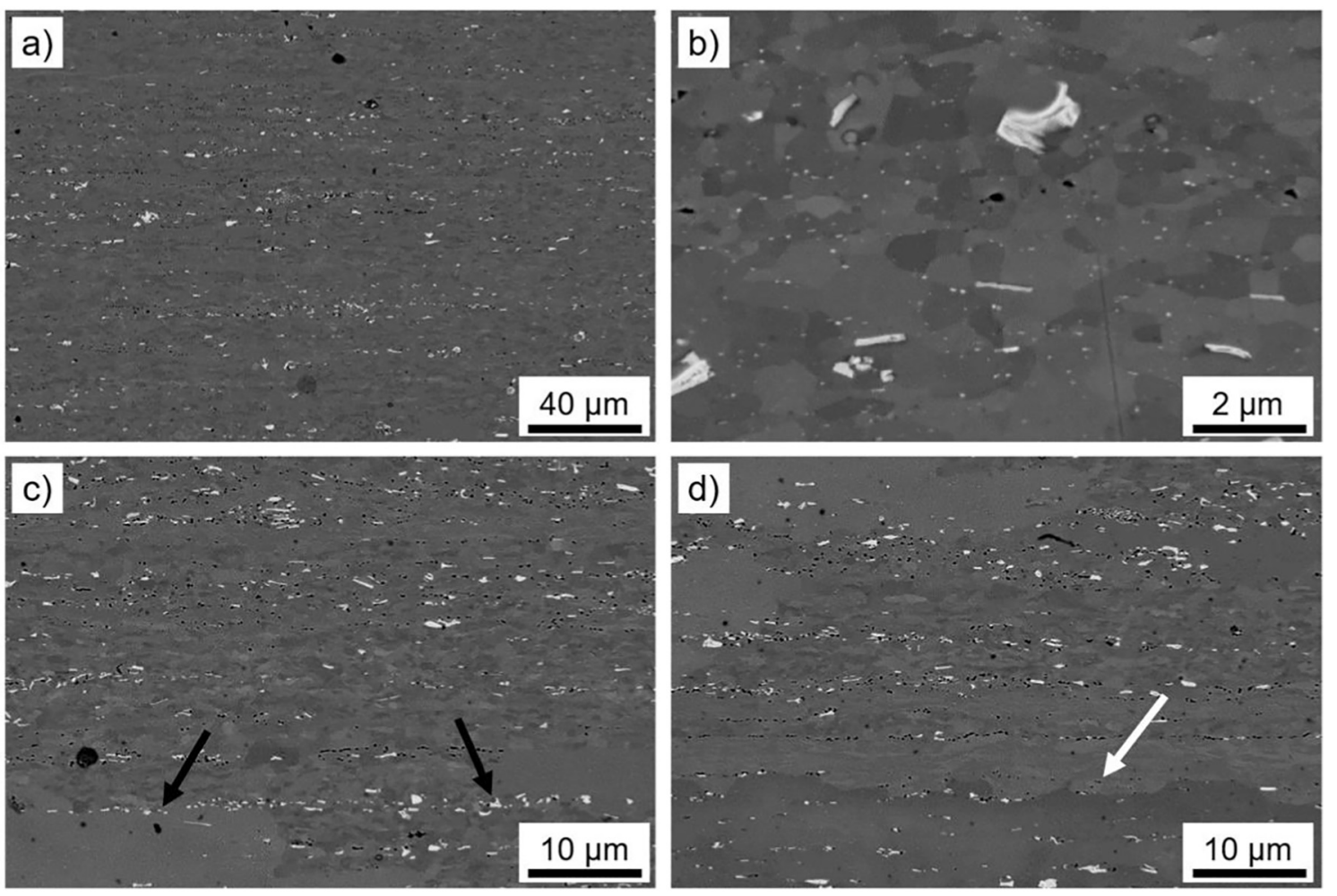

Fig. 9. SEM BSE micrographs showing the C1-2 sample deformed to $\varepsilon=3.0$ and annealed at $300{ }^{\circ} \mathrm{C}$ for $10^{5} \mathrm{~s}$. a) global view; b) pinned subgrain boundaries; c) elongated grains separate by constituent particles; d) elongated grain.

$\langle 001\rangle$ is often used since it promotes pronounced earing at the $0 / 90^{\circ}$ directions during deep drawing. In our case, for the C1-3 sample deformed to $\varepsilon=3.0$ and annealed at $500{ }^{\circ} \mathrm{C}$ for $10^{5} \mathrm{~s}$, a sharp cube texture is indeed obtained with intensity of 17.2, as illustrated in Fig. 10b. The corresponding fine grain structure is shown in Fig. $7 \mathrm{i}$ where it can be seen that the sizes of grains of different orientations are similar, excluding the possibility of any significant oriented growth of cube grains. Cube-oriented grains may stem from Cube-bands in the deformed structures, which are either Cube-oriented grains present already in the undeformed matrix but retained their orientation, or transition bands formed by splitting of unstable orientations during deformation [36]. Considering that the main deformation texture components of this alloy after cold rolling are S, Brass and Copper [18], the latter mechanism is more likely. In fact, a strong cube texture was not obtained by the C1-0 sample deformed to $\varepsilon=0.7$ and annealed at $500{ }^{\circ} \mathrm{C}$ for $10^{5} \mathrm{~s}$ (see Fig. 10a) possibly because transition bands with cube orientation have not yet been formed at this small deformation.

It can be envisaged that, for applications other than deep drawing, distinctly different texture components might be needed. The texture of the C1-0 sample deformed to $\varepsilon=3.0$ and annealed at $400{ }^{\circ} \mathrm{C}$ for $10^{5} \mathrm{~s}$ (see Fig. 10c) is primarily composed of $\mathrm{P}$ orientation $\left\{\begin{array}{lll}0 & 1 & 1\end{array}\right\}\langle 566\rangle$ and ND-rotated cube orientation $\left\{\begin{array}{llll}0 & 0 & 1\end{array}\right\}\langle 566\rangle$, see the corresponding microstructure in Fig. $5 \mathrm{~h}$. It is reminded here again that $\mathrm{C1}-0$ variant has the strongest precipitation potential. These two texture components are documented to form during recrystallization with strong concurrent precipitation, as detailed in Refs $[4,12,17,37-40]$. The factors affecting the strength of the $\mathrm{P}$ texture component during annealing of the same alloy has been investigated in an earlier study [41], paving the way to tailor it using different deformation and annealing conditions.

Even though not presented here, other texture components with different intensities can also be obtained when prior cold deformation, homogenization procedures and annealing conditions are varied. It is recalled here that tailoring crystallographic textures through this route is easy to be adopted in industrial practice, since the prior cold deformation and homogenization procedures can be easily changed using existing rolling machines and heat treatment furnaces, respectively.

\section{Conclusions}

In this study, a detailed investigation on the microstructural evolution of an Al-Mn alloy during isothermal annealing has been carried out. Starting from the same material, distinctly different recrystallization and precipitation kinetics, grain structures and crystallographic textures have been observed when the homogenization procedure and the prior cold rolling deformation are changed. The following conclusions can be drawn:

1) Large deformation promotes recrystallization and precipitation due to their high stored energy and more potential nucleation sites, respectively. Recrystallization is retarded by precipitation through the suppression of nucleation and pinning of grain boundary migration, on the other hand, recrystallization also delays precipitation by sweeping the deformation structure behind the moving grain boundaries and thus reducing the availability of potential heterogeneous nucleation sites.

2) Equiaxed grain structures were obtained when recrystallization is not affected by fine second phase particles, either for samples with insignificant pre-existing dispersoids and concurrent precipitation or when concurrent precipitation is avoided due to the fast recrystallization. Coarse elongated grain structure was ascribed to the combined effects of elongated deformation structure, suppressed nucleation and preferential growth of certain orientations.

3) Different crystallographic textures, including the near random texture, cube texture, P and ND-rotated cube textures, which are desired for various applications of Al-Mn alloys were obtained simply through the combined variation of homogenization processes and prior cold deformation. 
a)

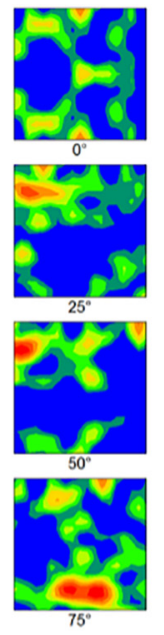

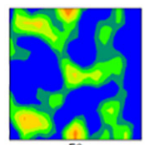
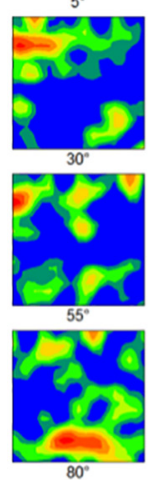
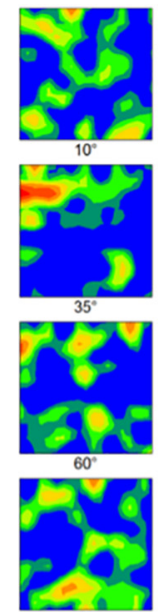

c)
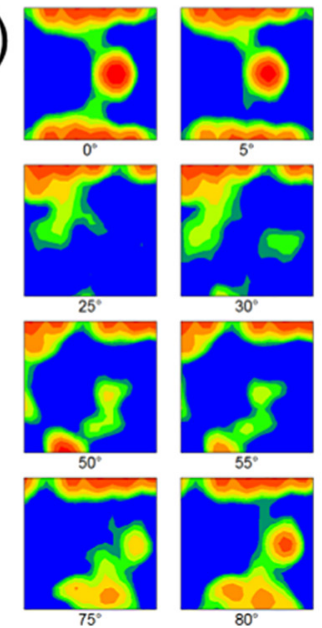

b)
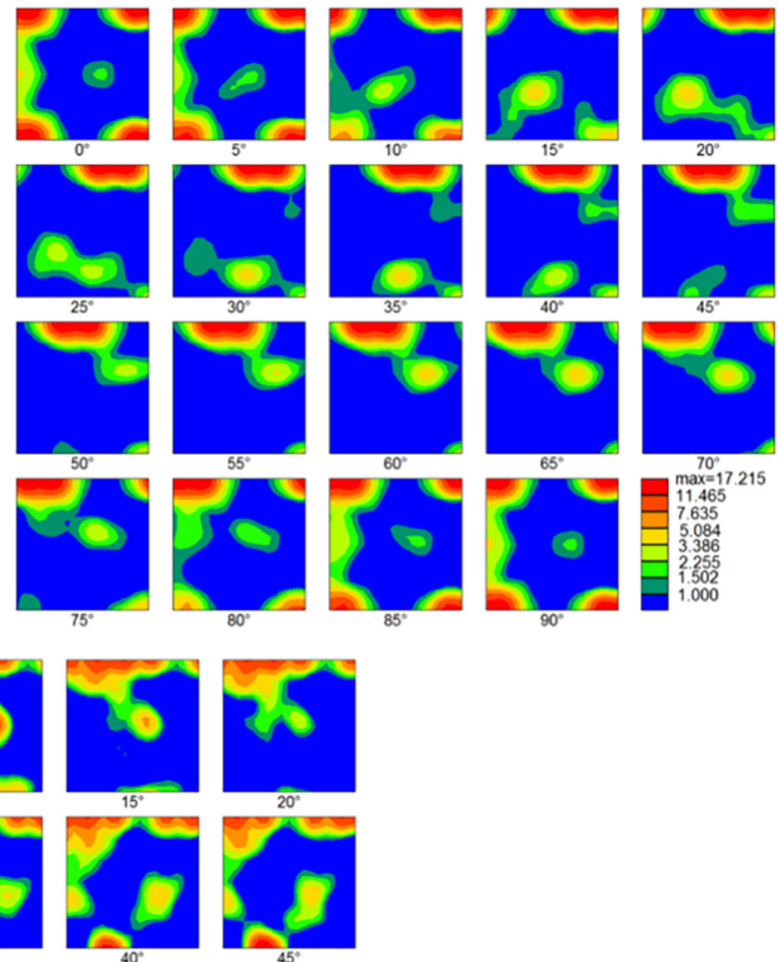

$35^{\circ}$
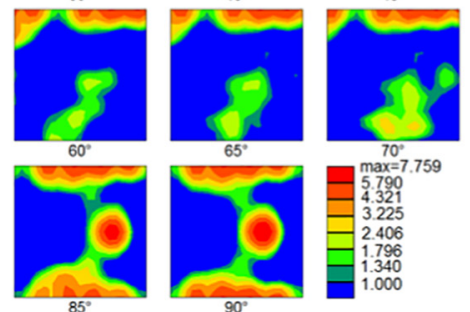

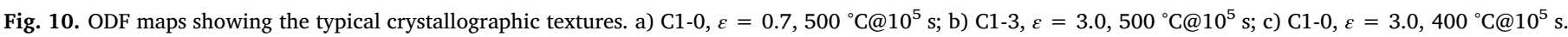

\section{Declaration of competing interest}

The authors declare that they have no known competing financial interests or personal relationships that could have appeared to influence the work reported in this paper.

\section{Acknowledgements}

The authors would like to acknowledge the financial support from the National Natural Science Foundation of China [51805415], the Natural Science Basis Research Plan in Shaanxi Province of China [Program No. 2019JM-125], the Fundamental Research Funds for the Central Universities [xzd012019033] and the Open Research Fund of State Key Laboratory of High Performance Complex Manufacturing, Central South University [Kfkt2018-04].

\section{Data availability}

The raw/processed data required to reproduce these findings cannot be shared at this time as the data also forms part of an ongoing study.

\section{References}

[1] Y.J. Li, L. Arnberg, Quantitative study in the precipitation behavior of dispersoids in DC-cast AA3003 alloy during heating and homogenization, Acta Mater. 51 (2003) 3415-3428.

[2] Y.J. Li, L. Arnberg, Evolution of eutectic intermetallic particles in DC-cast AA3003 alloy during heating and homogenization, Mater, Sci. Eng. A 347 (2003) 130-135.

[3] K. Huang, N. Wang, Y.J. Li, K. Marthinsen, The influence of microchemistry on the softening behaviour of two cold-rollled Al-Mn-Fe-Si alloys, Mater. Sci. Eng. A 601 (2014) 86-96.

[4] S. Tangen, K. Sjølstad, T. Furu, E. Nes, Effect of concurrent precipitation on recrystallization and evolution of the p-texture component in a commercial Al-Mn alloy, Metall. Mater. Trans. A 41A (2010) 2970-2983.

[5] J. Humphreys, G.S. Rohrer, A. Rollett, Recrystallization and Related Annealing Phenomena, 3rd ed., Elsevier, Oxford, 2017.

[6] K. Huang, K. Marthinsen, Q.L. Zhao, R.E. Logé, The double-edge effect of secondphase particles on the recrystallization behaviour and associated mechanical properties of metallic materials, Prog. Mater. Sci. 92 (2018) 284-359.

[7] R.D. Doherty, Recrystallization and texture, Prog. Mater. Sci. 42 (1997) 39-58.

[8] O.V. Mishin, D. Juul Jensen, N. Hansen, Evolution of microstructure and texture during annealing of aluminium AA1050 cold rolled to high and ultrahigh strains, Metall. Mater. Trans A 41 (2010) 2936-2948.

[9] J.J. Sidor, K. Decroos, R.H. Petrov, L.A.I. Kestens, Evolution of recrystallization textures in particle containing Al alloys after various rolling, Int. J. Plast. 66 (2015) 119-137.

[10] S. Mishra, K. Kulkarni, N.P. Gurao, Effect of crystallographic texture on precipitation induced anisotropy in an aluminium magnesium silicon alloy, Mater. Des. 87 (2015) 507-519.

[11] K. Huang, K. Zhang, K. Marthinsen, R.E. Logé, Controlling grain structure and texture in Al-Mn alloy from the competition between precipitation and recrystallization, Acta Mater. 141 (2017) 360-373.

[12] K. Huang, O. Engler, Y.J. Li, K. Marthinsen, Evolution in microstructure and properties during non-isothermal annealing of a cold-rolled Al-Mn-Fe-Si alloy with different microchemistry states, Mater. Sci. Eng. A 628 (2015) 216-229.

[13] Q.L. Zhao, K. Huang, Y.J. Li, K. Marthinsen, Orientation preference of recrystallization in supersaturated aluminum alloys influenced by concurrent precipitation, Metall. Mater. Trans A (2016) 1378-1388.

[14] M. Somerday, F.J. Humphreys, Recrystallisation behaviour of supersaturated Al-Mn alloys. Part 1 - Al-1.3 wt-\%Mn, Mater. Sci. Technol. 19 (2003) 20-29.

[15] O. Daaland, E. Nes, Recrystallization texture development in commercial Al-Mn-Mg alloys, Acta Mater. 44 (1996) 1413-1435.

[16] W.C. Liu, J.G. Morris, Evolution of recrystallization and recrystallization texture in continuous-cast AA 3015 aluminum, Metall. Mater. Trans. A 36 (2005) 2829-2848.

[17] C. Schäfer, G. Gottstein, The origin and development of the $\mathrm{P}\{011\}\langle 111\rangle$ 
orientation during recrystallization of particle-containing alloys, Int. J. Mater. Res. 102 (2011) 1106-1114.

[18] K. Huang, K. Marthinsen, The effect of heating rate on the softening behaviour of a deformed Al-Mn alloy with strong and weak concurrent precipitation, Mater. Charact. 110 (2015) 215-221.

[19] W.C. Liu, Z. Li, C.-S., Effect of heating rate on the microstructure and texture of continuous cast AA 3105 aluminum alloy, Mater. Sci. Eng. A 47 (2008) 173-180.

[20] N. Sun, B.R. Patterson, J.P. Suni, et al., Effect of heating rate on recrystallization of twin roll cast aluminum, Metall. Mater. Trans A 39 (2008) 165-170.

[21] L. Huang, G.J. Huang, L.F. Cao, X.D. Wu, Z.H. Jia, M.Y. Xia, Q. Liu, Influence of prerecovery on the subsequent recrystallization and mechanical properties of a twinroll cast Al-Mn alloy, Mater. Sci. Eng. A 682 (2017) 63-72.

[22] K. Huang, Q.L. Zhao, Y.J. Li, K. Marthinsen, Two-stage annealing of a cold-rolled $\mathrm{Al}-\mathrm{Mn}-\mathrm{Fe}-\mathrm{Si}$ alloy with different microchemistry states, J. Mater. Process. Technol. 221 (2015) 87-89.

[23] K. Huang, R.E. Logé, K. Marthinsen, On the sluggish recrystallization of a cold-rolled Al-Mn-Fe-Si alloy, J. Mater. Sci. 51 (2016) 1632-1643.

[24] F.J. Humphreys, The nucleation of recrystallization at second phase particles in deformed aluminium, Acta Metall. 25 (1977) 1323-1344.

[25] K. Huang, Y.J. Li, K. Marthinsen, Isothermal annealing of cold-rolled Al-Mn-Fe-Si alloy with different microchemistry states, Trans. Nonferrous Metals Soc. China 24 (2014) 3840-3847.

[26] C.S. Smith, Introduction to grains, phases, and interfaces: an interpretation of microstructure, Trans. AIME 175 (1948) 15-51.

[27] E. Nes, N. Ryum, O. Hunderi, On the Zener drag, Acta Metall. 33 (1985) 11-22.

[28] D. Juul Jensen, Growth rates and misorientation relationships between growing nuclei/grains and the surrounding deformed matrix during recrystallization, Acta Metall. Mater. 43 (1995) 4117-4129.

[29] Y. Ushigami, K. Kawasaki, T. Nakazama, Y. Suga, J. Harase, N. Takahashi, Dynamic observation of the growth of secondary recrystallized grains of Fe-35 Si alloy utilizing synchrotron X-ray topography, Mater. Sci. Forum 157-162 (1994) (1081-
1086-323).

[30] H. Homma, B. Hutchinson, Orientation dependence of secondary recrystallisation in silicon-iron, Acta Mater. 51 (2003) 3795-3805.

[31] F.J. Humphreys, M.G. Ardakani, Grain boundary migration and Zener pinning in particle-containing copper crystals, Acta Mater. 44 (1996) 2717-2727.

[32] D. Raabe, K. Lücke, Selective particle drag during primary recrystallization of Fe-Cr alloys, Scr. Metall. 26 (1992) 19-24.

[33] P.A. Beck, P.R. Sperry, H. Hu, The orientation dependence of the rate of grain boundary migration, J. Appl. Phys. 21 (1950) 420-425.

[34] G.H. Fan, Y.B. Zhang, J.H. Driver, D. Juul Jensen, Oriented growth during recrystallization revisited in three dimensions, Scr. Mater. 72-73 (2014) 9-12.

[35] Z. Zhao, W. Mao, F. Roters, D. Raabe, A texture optimization study for minimum earing in aluminium by use of a texture component crystal plasticity finite element method, Acta Mater. 52 (2004) 1003-1012.

[36] I.L. Dillamore, H. Katoh, The mechanisms of recrystallization in cubic metals with particular reference to their orientation-dependence, Metal Sci. 8 (1974) 73-83.

[37] Q. Zeng, X. Wen, T. Zhai, Effect of precipitates on the development of P orientation $\{011\}\langle 566\rangle$ in a recrystallized continuous cast AA3004 aluminium alloy after cold rolling, Metall. Mater. Trans A 40A (2009) 2488-2497.

[38] W.C. Liu, H. Yuan, M.J. Huang, Effect of rolling reduction on the P $\{011\}<455>$ recrystallization texture in a supersaturated Al-Mn-Mg alloy, Metall. Mater. Trans A 40A (2009) 2794-2797.

[39] J. Jung, J.I. Yoon, D.N. Lee, H.S. Kim, Numerical analysis on the formation of Porientation near coarse precipitates in FCC crystals during recrystallization, Acta Mater. 131 (2017) 363-372.

[40] O. Engler, P. Yang, X.W. Kong, On the formation of recrystallization textures in binary $\mathrm{Al}-1.3 \% \mathrm{Mn}$ investigated by means of local texture analysis, Acta Mater. 44 (1996) 3349-3369.

[41] K. Huang, Y.J. Li, K. Marthinsen, Factors affecting the strength of P $\{011\}\langle 566\rangle$ texture after annealing of a cold-rolled Al-Mn-Fe-Si alloy, J. Mater. Sci. 50 (2015) 5091-5103. 